\title{
The Long-Term Fate of Copper Fertilizer Applied to a Lateritic Sandy Soil in Western Australia
}

\author{
R. G. McLaren and G. S. P. Ritchie
}

\begin{abstract}
A soil copper fractionation was carried out on soils sampled from plots in a long-term copper fertilizer trial on a lateritic sandy soil in Western Australia. At copper application rates up to $8.25 \mathrm{~kg}$ copper sulphate $\mathrm{ha}^{-1}$, a high proportion of the applied copper was initially associated with the soil organic matter. During the course of the trial (20 years), a substantial proportion of this copper became redistributed to a residual soil fraction, i.e. the residue remaining after extractions to remove organic matter and iron oxides. However, significant redistribution of copper with time was not detected in plots with a higher rate of copper application $\left(19.25 \mathrm{~kg}\right.$ copper sulphate $\left.\mathrm{ha}^{-1}\right)$. The change in distribution of copper at the lower copper application rates appeared to be only partly responsible for a corresponding decrease observed in EDTA-extractable soil copper during the trial. The changes with time in the nature of fertilizer copper applied to this soil are considered to be responsible for the previously observed decline in plant availability of such copper.
\end{abstract}

\section{Introduction}

It has been demonstrated in glasshouse studies using an incubation technique (Brennan et al. 1980, 1983, 1984), that the availability to plants of copper applied to a range of Western Australian soils declines with increasing time of contact between soil and copper. A similar decline in availability has also been demonstrated with samples of soil obtained from a long-term copper fertilizer field experiment (Brennan et al. 1986). This observed decline in copper availability has been interpreted as resulting from slow reactions which convert a proportion of applied copper into forms of lower plant availability (Brennan et al. 1980). However the nature of these reactions is unclear. Involvement of the soil microbial population or reaction with soil organic matter appears to be of importance in reducing copper availability in some soils but not in others (Brennan et al. 1983). In general, decreases in the availability of applied copper to plants have not been mirrored by corresponding changes in the extractability of copper in the soil (Brennan et al. 1980, 1986).

In the present study we have used a chemical fractionation scheme to examine the forms of copper present in samples of soils from a long-term copper fertilizer trial (Gartrell 1980). The main objective was to determine any changes with time which might account for the observed decline in copper availability to plants. 


\section{Materials and Methods}

\section{Soil Sampling}

Soil was collected from selected plots of an experiment described by Gartrell (1980). The experiment was located at Newdegate on a yellow brown lateritic sandy soil classified as Gn 2.21 according to Northcote (1971). The soil contains very little clay and silt (less than $6 \%$ ), being dominated by sand-sized particles $(>0.02 \mathrm{~mm})$. The soil $\mathrm{pH}(1: 5$ water) was 5.5 , the organic carbon $1.0 \%$ and the oxalate-extractable iron and aluminium (Shuman 1985) $0.19 \%$ and $0.04 \%$ respectively.

The design of the main experiment is complex and full details are given by Gartrell (1980). However in relation to the present study, the detail of importance is that at various times over the past 20 years, subplots have received single applications of copper sulphate $\left(\mathrm{CuSO}_{4} \cdot 5 \mathrm{H}_{2} \mathrm{O}\right)$ at a rate of either $2 \cdot 75,5 \cdot 5$ or $8 \cdot 75 \mathrm{~kg} \mathrm{ha}^{-1}$. These subplots were subsequently excluded from the remaining main plots and received no further applications of copper.

In 1990, the surface 0-10 cm of soil from selected subplots from a single main plot (initially treated in 1969) were sampled. The subplots sampled are shown in Table 1.

Table 1. Plots sampled

\begin{tabular}{cccccc}
\hline $\begin{array}{c}\text { Date Cu } \\
\text { applied }\end{array}$ & $\begin{array}{c}\text { Copper sulphate } \\
\text { applied } \\
\left(\mathrm{kg} \mathrm{ha}^{-1}\right)\end{array}$ & $\begin{array}{c}\text { Time since Cu } \\
\text { applied } \\
\text { (years) }\end{array}$ & $\begin{array}{c}\text { Date Cu } \\
\text { applied }\end{array}$ & $\begin{array}{c}\text { Copper sulphate } \\
\text { applied } \\
\left(\mathrm{kg} \mathrm{ha}^{-1}\right)\end{array}$ & $\begin{array}{c}\text { Time since Cu } \\
\text { applied } \\
\text { (years) }\end{array}$ \\
\hline- & 0 (control) & - & - & - & - \\
1969 & $2 \cdot 75$ & 20 & 1981 & $8 \cdot 25$ & 8 \\
1973 & $2 \cdot 75$ & 16 & 1985 & $8 \cdot 25$ & 4 \\
1977 & $2 \cdot 75$ & 12 & 1989 & $8 \cdot 25$ & 0 \\
1981 & $2 \cdot 75$ & 8 & 1969 & 11 & 20 \\
1985 & $2 \cdot 75$ & 4 & $1973^{\mathrm{A}}$ & $11+8 \cdot 25$ & 16 \\
1989 & $2 \cdot 75$ & 0 & $1977^{\mathrm{A}}$ & $11+8 \cdot 25$ & 12 \\
1969 & $8 \cdot 25$ & 20 & $1981^{\mathrm{A}}$ & $11+8 \cdot 25$ & 4 \\
1973 & $8 \cdot 25$ & 16 & $1985^{\mathrm{A}}$ & $11+8 \cdot 25$ & 0 \\
1977 & $8 \cdot 25$ & 12 & $1989^{\mathrm{A}}$ & $11+8 \cdot 25$ & 4 \\
\hline
\end{tabular}

A $11 \mathrm{~kg} \mathrm{ha}^{-1}$ applied in 1969.

Table 2. Sequential extraction method for the determination of forms of copper in soils (adapted from Shuman 1985)

\begin{tabular}{|c|c|c|c|c|c|}
\hline Step & Fraction & Extractant & $\begin{array}{l}\text { Soil } \\
(\mathrm{g})\end{array}$ & $\begin{array}{l}\text { Solution } \\
\text { (ml) }\end{array}$ & Conditions \\
\hline 1. & Exchangeable $\mathrm{Cu}$ & $0.01 \mathrm{M}$ calcium nitrate & 5 & 35 & Shaken $24 \mathrm{~h}$ \\
\hline 2. & Organic-bound $\mathrm{Cu}$ & $\begin{array}{l}0.7 \mathrm{M} \text { sodium hypochlorite } \\
(\mathrm{pH} 8.5)\end{array}$ & $10^{\mathrm{A}}$ & 20 & $\begin{array}{l}\text { Boiling water bath } \\
30 \text { min stirred } \\
\text { occasionally } \\
\text { (repeated } \times 2 \text { ) }\end{array}$ \\
\hline 3. & $\begin{array}{l}\mathrm{Cu} \text { associated with } \\
\text { iron oxides }\end{array}$ & $\begin{array}{l}0.2 \mathrm{M} \text { ammonium oxalate } \\
0.2 \mathrm{M} \text { oxalic acid } \\
0.1 \mathrm{M} \text { ascorbic acid }(\mathrm{pH} 3)\end{array}$ & $1^{B}$ & 25 & $\begin{array}{l}\text { Boiling water bath } \\
30 \text { min stirred } \\
\text { occasionally }\end{array}$ \\
\hline 4. & Residual $\mathrm{Cu}$ & $\begin{array}{l}\text { concentrated nitric, } \\
\text { perchloric and hydrofluoric } \\
\text { acids }(3: 1: 10)\end{array}$ & $1^{\mathrm{C}}$ & 13 & $\begin{array}{l}\text { Digested at } 160^{\circ} \mathrm{C} \\
\text { in teflon beaker on } \\
\text { sand bath }\end{array}$ \\
\hline
\end{tabular}

\footnotetext{
A Separate sample from step $1 . \quad{ }^{\text {B }} 1 \mathrm{~g}$ from step 2 after drying and grinding. $\quad{ }^{C}$ Residue
} form step 3 . 
For all plots treated with copper before 1989 , the soil $(0-10 \mathrm{~cm})$ was collected by taking a number of cores per plot with a sampling tool $2.5 \mathrm{~cm}$ in diameter. For those plots treated in 1989, since copper sulphate had been drilled with the seed and, unlike the other plots, not mixed subsequently by cultivation, a different sampling strategy was adopted. At six points along the plot length; soil was collected from small $10 \mathrm{~cm}$ deep trenches dug across the entire width of the plots. For both types of sampling a total of approximately $2 \mathrm{~kg}$ soil was collected per plot.

The soil was air-dried and passed through a $2 \mathrm{~mm}$ stainless steel sieve and stored in polythene bags until analysed.

\section{Fractionation of Soil Copper}

A sequential extraction method, adapted from that described by Shuman (1985), was used to fractionate the soil copper. Details of the method are shown in Table 2. The method fractionated soil copper into the following four fractions: 1. exchangeable copper; 2. organic-bound copper; 3.copper associated with iron oxides; 4 . residual copper (copper remaining after removal of first three fractions).

The original fractionation of Shuman (1985), includes an extraction for the removal of micronutrients bound by free manganese oxides. This step was omitted from the present scheme since initial studies showed negligible amounts of manganese were removed from the study soil by such an extraction. The Shuman (1985) scheme also separates micronutrients associated with amorphous iron oxides from those associated with crystalline iron oxides. However several of the soil samples examined in the present study had such small amounts of copper associated with iron oxides that separation into two fractions was not considered practical.

In addition to the fractionation, the total copper content was determined by means of a single digestion of samples with nitric, perchloric and hydrofluoric acids using the same procedure as for residual copper (Table 2).

Particle size fractions (sand, $2 \mathrm{~mm}-0.02 \mathrm{~mm}$; silt, $0.02-0.002 \mathrm{~mm}$ and clay, $<0.002 \mathrm{~mm}$ ) were obtained from a sample of control soil by a combination of sieving and sedimentation techniques. Total copper (and iron) was determined in the individual particle size fractions.

All determinations were carried out in duplicate.

\section{EDTA-extractable Copper}

Samples of soil ( $10 \mathrm{~g}$ in duplicate) were extracted for $16 \mathrm{~h}$ on an end-over-end shaker with $25 \mathrm{~mL} 0.005 \mathrm{M}$ EDTA (disodium salt of ethylene diaminetetraacetic acid in $0.01 \mathrm{M}$ $\left.\mathrm{Ca}\left(\mathrm{NO}_{3}\right)_{2}\right)$. The samples were then centrifuged at $2000 \mathrm{rpm}$ for 10 minutes before filtering through a $0.65 \mu \mathrm{m}$ millipore filter. Copper was determined in the filtrate as described below.

\section{Copper Adsorption Isotherms}

Copper adsorption isotherms were determined for soil sampled from the control plot together with subsamples of the same soil treated to remove organic matter and/or iron oxides. Organic matter and iron oxides were removed using the same methods as in the fractionation scheme (Table 2). Although the measurement of adsorption after removal of soil components can provide useful qualitative information on the relative importance of different soil components, the technique is not without its limitations. Extraction methods are never $100 \%$ specific for a particular soil component; some loss of other soil components can occur, or the removal of one fraction may expose sites which are unavailable for adsorption in the intact soil. Thus any interpretation of adsorption data obtained in this way must bear these limitations in mind.

Copper adsorption (specific adsorption) for both the untreated and treated samples of soil were determined as follows:

Samples of soil $(0.5 \mathrm{~g}$ in duplicate) were equilibrated with $10 \mathrm{~mL}$ solution containing known amounts of copper (as $\mathrm{Cu}\left(\mathrm{NO}_{3}\right)_{2}$ in $\left.0.01 \mathrm{M} \mathrm{Ca}\left(\mathrm{NO}_{3}\right)_{2}\right)$. Equilibration was carried out in centrifuge tubes on an end-over-end shaker for $24 \mathrm{~h}$ at $25^{\circ} \mathrm{C}$. The samples were then centrifuged 
and filtered and copper determined in the filtrate. Copper adsorbed was calculated from the initial and final solution copper concentrations. Equilibrium solutions from the untreated soil had $\mathrm{pH}$ values in the range $4 \cdot 4-4 \cdot 9$. For the samples treated to remove organic matter and/or oxides it was necessary to include small amounts of $\mathrm{NaOH}(0.1 \mathrm{M})$ or $\mathrm{HNO}_{3}(0.5 \mathrm{M})$ in the initial solution to ensure that the $\mathrm{pH}$ values of the equilibrium solutions were in this same range (i.e. $\mathrm{pH} 4 \cdot 4-4 \cdot 9$ ).

\section{Copper Analysis}

Copper concentrations in soil extracts, digests and equilibrium solutions were determined by flame atomic absorption spectrophotometry. For samples where only small volumes of solution were available for analysis, solutions were aspirated by injection into a teflon cup as described by Manning (1975), rather than by continuous aspiration.

\section{Statistical Analyses}

All data given in this paper are the mean values from duplicate analyses. Standard errors were calculated using normal statistical procedures. 'Straight line' Langmuir adsorption equations were derived by linear regression thus enabling standard errors of the $\mathrm{Cu}$ adsorption capacities to be calculated.

\section{Results}

\section{Total Soil Copper Concentrations}

Total copper concentrations in the control soil and the mean concentrations in samples from the plots at each application rate are shown in Table 3. Mean recoveries of applied copper (control value subtracted) together with the calculated maximum possible recoveries are also presented in Table 3 . The calculated maximum possible recoveries are based on the assumption that all the applied copper remained in the top $10 \mathrm{~cm}$ of soil (sampling depth) and that the soil has a bulk density of $1.5 \mathrm{~g} \mathrm{~cm}^{-3}$ (Gartrell, 1980). It is clear that the bulk of the copper applied still remains in the soil, particularly at the two lower application rates.

Table 3. Total soil copper concentrations and recoveries of applied copper

\begin{tabular}{llcc}
\hline \multicolumn{1}{c}{ Sample } & $\begin{array}{c}\text { Total Cu } \\
\left(\mu \mathrm{g} \mathrm{g}^{-1} \pm \text { s.e. }\right)\end{array}$ & $\begin{array}{c}\text { Applied Cu } \\
\text { recovered } \\
\left(\mu \mathrm{g} \mathrm{g}^{-1}\right)\end{array}$ & $\begin{array}{c}\text { Maximum } \\
\text { possible } \\
\text { Cu recovery } \\
\left(\mu \mathrm{g} \mathrm{g}^{-1}\right)\end{array}$ \\
\hline Control plot & $2 \cdot 08$ & & \\
$2 \cdot 75 \mathrm{~kg} \mathrm{ha}^{-1}$ copper sulphate & $2 \cdot 50 \pm 0 \cdot 07$ & $0 \cdot 42$ & $0 \cdot 45$ \\
$8 \cdot 25 \mathrm{~kg} \mathrm{ha}^{-1}$ copper sulphate & $3 \cdot 35 \pm 0 \cdot 21$ & $1 \cdot 27$ & $1 \cdot 35$ \\
$19 \cdot 25 \mathrm{~kg} \mathrm{ha}^{-1}$ copper sulphate $^{\mathrm{B}}$ & $4 \cdot 50 \pm 0 \cdot 11$ & $2 \cdot 42$ & $3 \cdot 15$ \\
\hline
\end{tabular}

s.e. standard error. ${ }^{A}$ Calculated. ${ }^{B}$ Mean of all plots with this rate of applied Cu.

Table 4. Propertions of total copper and iron present in particle size fractions from control soil

\begin{tabular}{lcc}
\hline $\begin{array}{l}\text { Particle size } \\
\text { fraction }\end{array}$ & $\begin{array}{c}\% \text { total } \\
\text { copper }\end{array}$ & $\begin{array}{c}\% \text { total } \\
\text { iron }\end{array}$ \\
\hline Sand & $87 \cdot 8$ & $89 \cdot 8$ \\
Silt & $6 \cdot 5$ & $5 \cdot 2$ \\
Clay & $5 \cdot 7$ & $5 \cdot 0$ \\
\hline
\end{tabular}


At each application rate there was some variation in total copper concentrations between plots treated at different times (as indicted by standard error values in Table 3), but no trends were discernible. Such variation would be expected in a trial carried out over a 20 year period where, in addition to normal sampling error, variations between plots in applications and subsequent mixing would have undoubtedly occurred. In order to minimise the effects of such variation in interpreting the data presented below, results for various soil copper fractions are expressed mainly as percentages of the total copper recovered on an individual sample basis rather than as copper concentrations.

The analysis of copper present in individual particle size fractions from the control soil showed that most native soil copper is present in the sand fraction (Table 4). This is also the case for iron.

\section{Copper Fractionation}

Attempts to determine exchangeable soil copper were unsuccessful for all samples. This is perhaps not surprising in view of the extremely low total soil

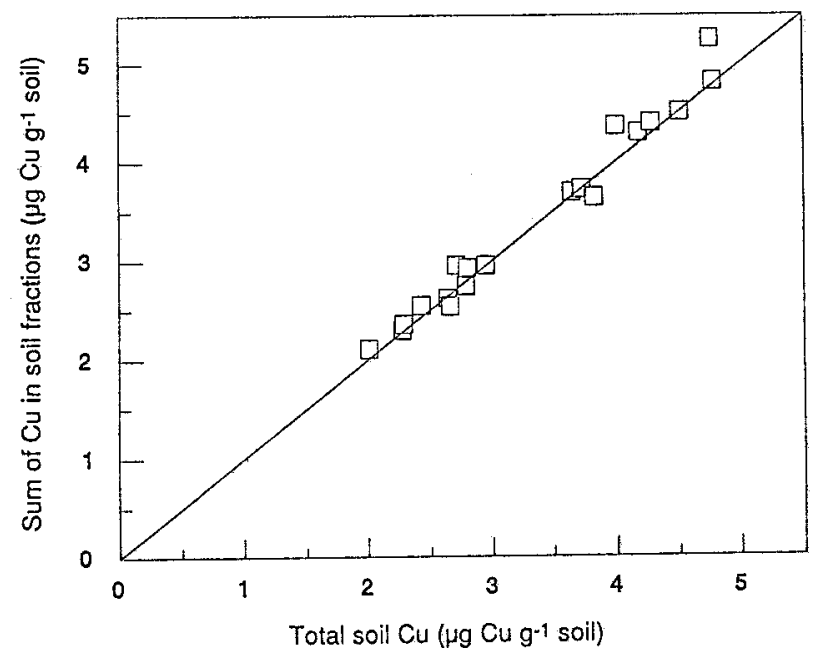

Fig. 1. Comparison of total soil copper concentrations with the sums of concentrations in individual fractions.

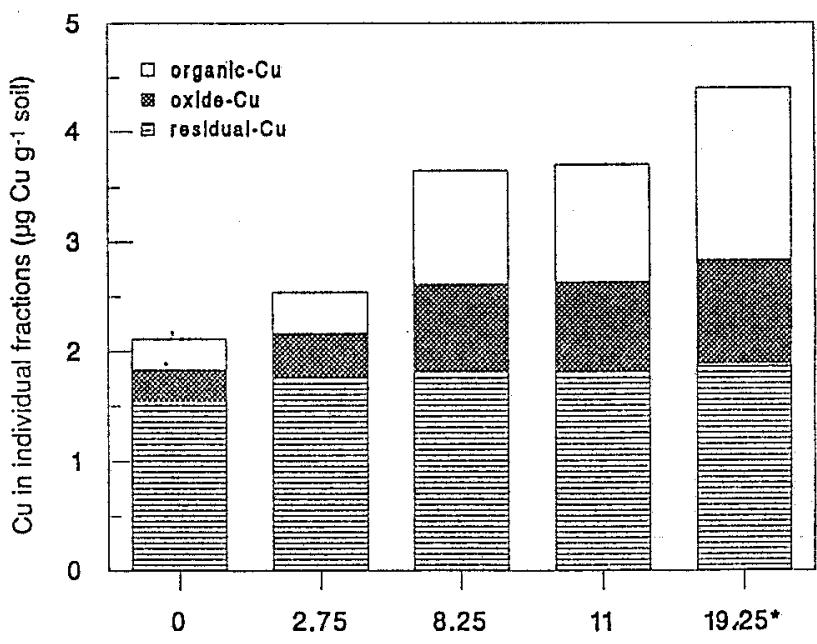

Fig. 2. Fractionation of copper in soil from plots treated with copper in 1969 $\left({ }^{*} 11 \mathrm{~kg} \mathrm{ha}^{-1}\right.$ in 1969 plus $8.25 \mathrm{~kg} \mathrm{ha}^{-1}$ in 1973).

Copper sulphate applied in 1969 (kg ha-1) 
(a) $2.75 \mathrm{~kg}$ copper sulphate ha.

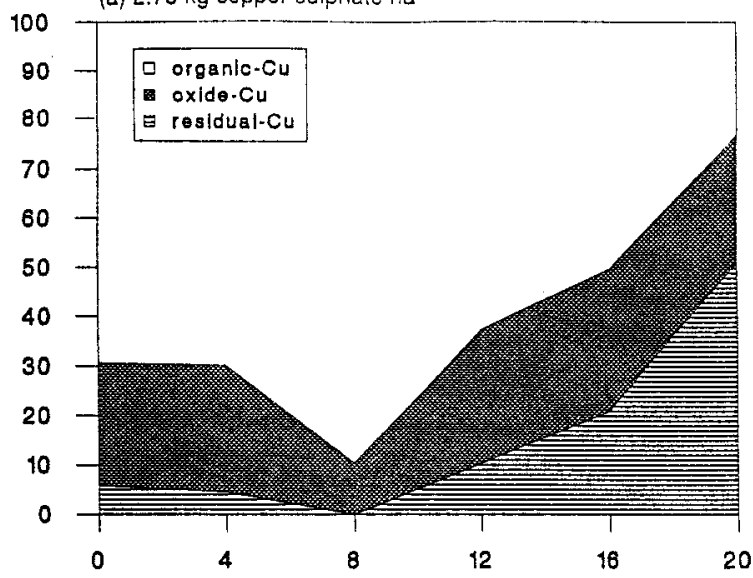

(b) $8.25 \mathrm{~kg}$ copper sulphate ha-1

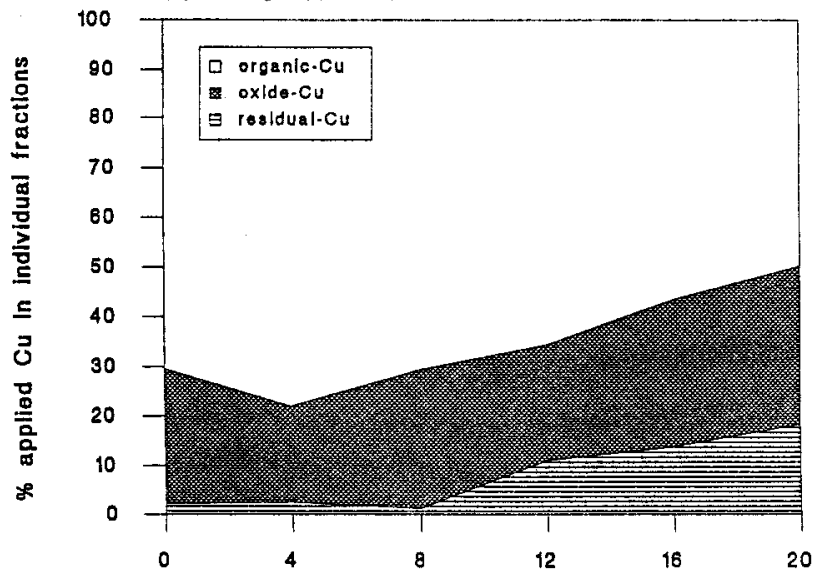

Fig. 3. Effect of time since application on the distribution of applied copper between soil fractions.

(c) $19.25 \mathrm{~kg}$ copper sulphate ha-1 ("only $11 \mathrm{~kg}$ copper sulphate ha-1)

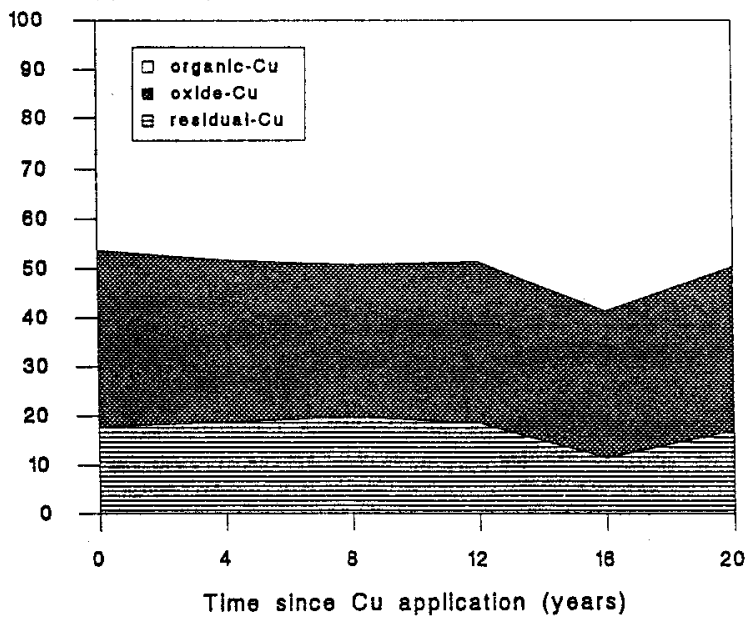


copper concentrations present in the samples. Copper concentrations in extracts for exchangeable copper were below the detection limits of the particular atomic absorption technique being used. In effect, exchangeable copper concentrations were all below $0.01 \mu \mathrm{g} \mathrm{Cu} \mathrm{g}^{-1}$ soil.

For the other three soil copper fractions (organic, iron oxide and residual), copper concentrations were generally low. However, confidence in the results obtained is given by the close agreement between the sum of copper in the individual fractions and the total copper concentration obtained by a single determination (Fig. 1).

The concentrations of copper in individual fractions of the control soil and the soils treated with copper in 1969 are shown in Fig. 2. In the control soil a large proportion of the total copper $(73 \%)$ is present in the residual fraction with the remaining copper distributed evenly between the organic-bound and iron oxide fractions. These latter two fractions account for most of the applied copper, irrespective of the rate of application. This is shown more clearly in Fig. 3 in which the applied copper in each fraction, expressed as a percentage of the total recovery of applied copper, is plotted against the period of time since copper application.

During the first 8 years, very little of the copper applied at the two smallest rates was present in the residual fraction; the bulk of the copper appearing in the organic-bound fraction. However, with increasing time since application there was a marked redistribution of copper from the organic-bound to the residual fraction, particularly noticeable at the lowest copper application rate. The proportions of applied copper present in the iron oxide fraction appeared to be unaffected by this redistribution and remained fairly constant throughout the whole period of the experiment.

In contrast to the lowest rate of copper application, at the highest rate there were no marked trends with time in the distribution of applied copper between the various fractions.

\section{EDTA-extractable Soil Copper}

EDTA-extractable copper values, expressed as percentages of the total recovery of applied copper, are shown in Fig. 4. At both the lower two copper application rates a high proportion (over 86\%) of the most recently applied copper was recovered by EDTA extraction. This proportion decreased substantially with increased time since application and, after 20 years at the lowest application rate, only $10 \%$ of the applied copper remaining in the soil could still be extracted with EDTA. At the middle application rate $\left(8.15 \mathrm{~kg}\right.$ copper sulphate $\left.\mathrm{ha}^{-1}\right), 23 \%$ of the applied copper remaining in the soil remained extractable with EDTA after 20 years.

At the highest copper application rate, the proportion of the most recently applied copper extractable with EDTA was much smaller than for the lower rates of application (Fig. 4). There appeared to be little change in this proportion during the whole period of the experiment.

\section{Copper Adsorption}

Copper adsorption isotherms for untreated soil from the control plot and samples from which organic matter and/or iron oxides had been removed are 
shown in Fig. 5. Adsorption capacities were determined by plotting the adsorption data in accordance with the Langmuir adsorption equation and deriving values for adsorption maxima from the gradients of the resulting straight line plots (McLaren and Crawford 1973b). Values for the adsorption maxima are presented in Table 5. The curves in Fig. 5 have been drawn using the Langmuir equations derived from the straight line plots.

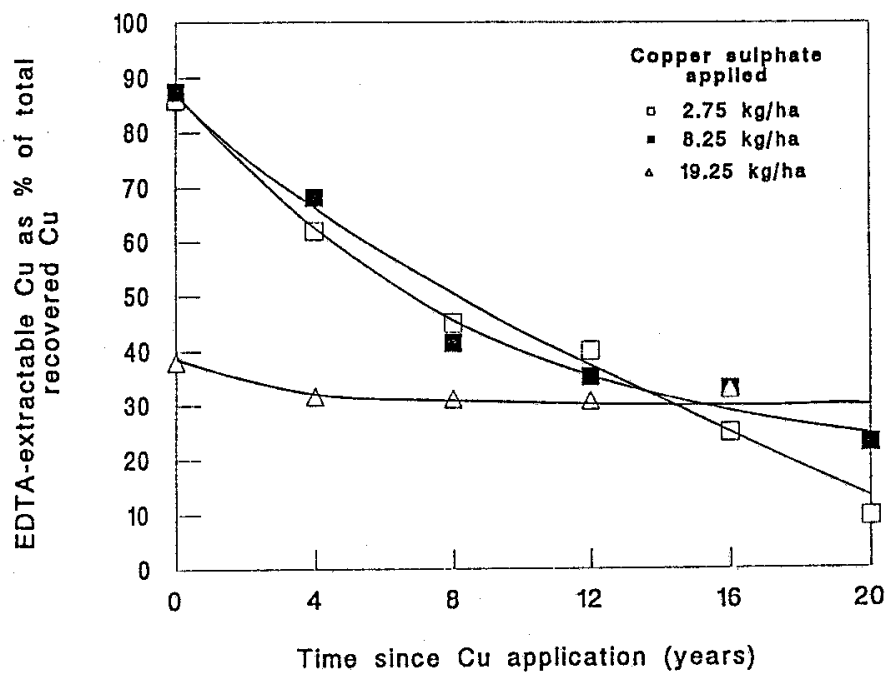

Fig. 4. Effect of time since application on the EDTA-extractability of applied copper.

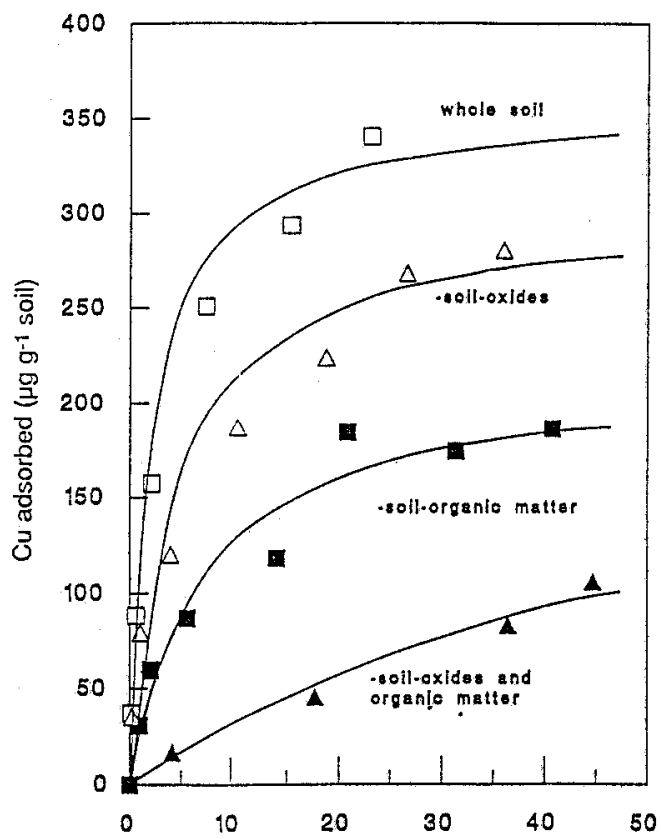

Fig. 5. Specific adsorption of copper by whole and treated soil.

Equilibrium solution $\mathrm{Cu}$ concentration $(\mu \mathrm{g} \mathrm{mil} \cdot 1)$ 
The solution copper concentrations used in determining the isotherms were much higher than would exist in soil solutions under normal field conditions. Such concentrations were used deliberately so that the forms of the complete isotherms could be determined, thus enabling fitting to the Langmuir equation and the calculation of maximum adsorption capacities. The derived Langmuir equations also make it possible to predict the copper concentrations adsorbed at low solution copper concentrations. For example, the predicted copper concentrations adsorbed by the whole and treated soil samples at an equilibrium solution copper concentration of $0.02 \mu \mathrm{g} \mathrm{mL}^{-1}$ are shown in Table 5. The predicted copper adsorbed by the whole soil at this solution concentration $\left(3.34 \mu \mathrm{g} \mathrm{g}^{-1}\right.$ soil) is approximately equivalent to the copper applied at the highest rate in the field trial. At the same solution copper concentration, removal of organic matter resulted in a predicted $80 \%$ reduction in copper adsorption, and the removal of iron oxide a predicted $55 \%$ reduction. The predicted copper adsorption by the residual soil fraction at this solution copper concentration was negligible (Table 5). However, with increasing solution copper concentrations, as a result of differences in the shapes of the various adsorption isotherms (Fig. 5) the relative importance for copper adsorption of organic matter and iron oxides decreases, and that of the residual soil fraction increases. The ultimate effect of this trend is clearly seen in the values for the maximum adsorption capacities (Table 5). Even after the treatments to remove both organic matter and iron oxides, the maximum capacity of the residue to adsorb copper remained substantial, being approximately $50 \%$ of the capacity of the whole soil.

Table 5. Copper adsorption capacities of whole and treated soil and predicted adsorption at a solution copper concentration of $0.02 \mu \mathrm{g} \mathrm{mL}^{-1}$

\begin{tabular}{lcc}
\hline \multicolumn{1}{c}{ Sample } & $\begin{array}{c}\text { Cu adsorption capacity } \\
\left(\mu \mathrm{g} \mathrm{Cu} \mathrm{g}^{-1} \text { soilts.e. }\right)\end{array}$ & $\begin{array}{c}\text { Predicted Cu adsorbed } \\
\text { at solution } \\
\text { Cu concn. of } 0 \cdot 02 \mu \mathrm{g} \mathrm{mL}^{-1} \\
\left(\mu \mathrm{g} \mathrm{Cu} \mathrm{g} \mathrm{goil}^{-1}\right)\end{array}$ \\
\hline Whole soil & $353 \pm 19$ & $3 \cdot 34$ \\
Soil-organic matter & $209 \pm 16$ & 0.67 \\
Soil-iron oxides & $296 \pm 20$ & $1 \cdot 49$ \\
Soil-organic matter and iron oxides & $183 \pm 71$ & 0.08 \\
\hline
\end{tabular}

A Derived from Langmuir isotherm. ${ }^{B}$ Calculated from Langmuir equations. s.e. standard error.

\section{Discussion}

The fractionation data and the EDTA-extractable $\mathrm{Cu}$ data both show changes with time in the ability of chemical reagents to recover applied copper from the soil. Since there has been little loss of copper from the soil during the period of the trial (20 years), the implication is that changes have occurred in the way in which the applied copper is associated with the various soil constituents. Initially, copper added to the soil at the two lower rates of application appeared to be mainly organic-bound (Fig. 3), whereas at the highest application rate, the added copper appeared to be distributed evenly between the organic matter and iron oxide fractions (Fig. 3). At the lowest copper application rate, the proportion of applied copper present in the organic-bound fraction decreased markedly during 
the period of the trial and was mirrored by an increase in the residual copper fraction (Fig. 3). Similar but less marked trends were observed at the middle copper application rate but not at the highest rate.

The apparent differences between the three application rates are most likely due to the amounts of copper actually involved in the redistribution from organic-bound to residual forms. For both the lower two application rates, the concentration of copper transformed from organic-bound to residual forms during the 20 years of the trial was approximately $0.2 \mu \mathrm{g} \mathrm{Cu} \mathrm{kg}^{-1}$ soil. This amount represents nearly $50 \%$ of the applied copper at the lowest rate of application and thus the change in form was detected quite readily. At the middle application rate, the amount redistributed represents approximately $15 \%$ of the copper applied, and although not as marked as at the lowest rate,the trends were still observed. However, even if the same amount of copper had changed fractions at the highest application rate, it would have accounted for only $6 \%$ of the copper applied and, with the sampling and analytical errors involved, would have been extremely difficult to detect.

In many soils, copper in the residual fraction copper would be regarded mainly as being present within the crystal structure of silicate minerals (predominantly phyllosilicates) e.g. McLaren and Crawford, 1973a. However in the lateritic soil under study this seems unlikely, and an alternative suggestion is that copper in the residual fraction is associated predominantly with iron oxide material. Nearly $90 \%$ of the iron in this soil is present in the sand fraction (Table 4) and thus is present in particles with small surface area to volume ratios. The iron in such a soil is also almost certainly present as strongly crystalline oxides. As a result of these two factors it is likely that the oxalate/ascorbic acid extraction used to remove 'iron oxides' is far less effective in this type of soil than in soils where most of the oxide material is present in the clay fraction and/or the iron oxides are less strongly crystalline. (The fact that nearly $60 \%$ of the total iron in the lateritic soil was present in the residual fraction after extraction with oxalate/ascorbic acid would support this view).

The observed changes with time in the distribution of applied copper between fractions are thus most probably a result of a redistribution of copper from organic sites to sites associated with strongly crystalline iron oxide materials. It is interesting to note that in the control soil, a high proportion $(73 \%)$ of the native soil copper is associated with the residual fraction (Fig. 2), and nearly $90 \%$ of the native copper is present in the sand fraction (Table 4). There appears to be little previous information on the redistribution of applied copper between fractions in field soils. However, in laboratory studies, McLaren et al. (1983) were able to induce some redistribution of copper between components in humic acid/soil oxide/montmorillonite systems. The impetus for redistribution of copper is most likely to be the slow movement of copper into solid oxide materials. Such movement has been observed by several researchers and is known to have extremely limited reversibility (Swift and McLaren 1991). Whether, as suggested by McBride (1991), such movement is due to solid diffusion into lattice structures or by penetration of extremely small pores and interparticle spaces, the net result is a reduction in the concentration of copper adsorbed at the surface of the oxide. This, in turn, would lead to the establishment of new equilibria between soil solution and surface adsorbed forms of copper including the copper adsorbed by soil organic matter. 
The copper adsorption data, bearing in mind its possible limitations, appears to support the results of the fractionation studies. At very low solution copper concentrations (as would be the situation at the field site), adsorption of copper appeared to be dominated by soil organic matter and to a lesser extent by iron oxides (Table 5). The effect of the residual fraction on copper adsorption increased with increasing solution copper concentration, and although insignificant at low concentrations, accounted for approximately half of the total capacity of the soil to adsorb copper (Table 5). It should also be remembered that copper adsorption was determined in the laboratory after only $24 \mathrm{~h}$, and over very much longer periods of time, even at low solution copper concentrations, the effect of the residual fraction on adsorption could be much more important.

The changes in the distribution of copper between fractions are reflected in the recovery of applied copper with EDTA, an extractant often used to assess soil copper availability to plants (Fig. 4). However the decreases in recovery of applied copper with EDTA are substantially greater than the decreases in organic-bound copper observed in the fractionation data. At the lowest rate of copper application, there was a $46 \%$ reduction in applied copper recovered as organic-bound copper but a $76 \%$ reduction in recovery of applied copper with EDTA. The corresponding figures for the middle rate of copper application were $21 \%$ and $76 \%$. It would appear therefore that the redistribution of copper from the organic-bound to residual fractions does not fully explain the reduction in EDTA extractability. There may well be other changes taking place with the applied copper, for instance movement to more strongly binding sites on soil organic matter, which the fractionation scheme fails to detect.

Nevertheless, it is clear that copper applied to the soil at the study site has undergone considerable changes during the 20 years of the trial. In particular, the changes appear to have had their greatest effect on the most labile and thus plant available forms of copper (as determined by EDTA extraction). It would also appear that such changes will be proportionately of greater importance at lower rates of copper application.

The changes to applied copper observed in this study are particularly interesting when compared with the results of plant copper uptake studies carried out using the same soil by Brennan et al., 1980, 1986. These researchers found that the availability of applied copper for uptake by wheat plants declined with time of contact between the soil and the applied copper. Although Brennan et al. (1980, 1986) were unable to demonstrate clear changes in soil copper extractability which mirrored the decline in plant copper uptake, they suggested that slow reactions between copper and the soil were responsible for the decline in plant availability. The results of the current study provide strong evidence in support of the existence of such reactions.

\section{Acknowledgments}

The authors are grateful to J. W. Gartrell of the Western Australian Department of Agriculture for permission to sample the Newdegate site. R. F. Brennan and D. Weaver are thanked for help with the field sampling and L. Hassall for technical assistance in the laboratory. 


\section{References}

Brennan, R. F., Gartrell, J. W., and Robson, A. D. (1980). Reactions of copper with soil affecting its availability to plants. I. Effect of soil type and time. Aust. J. Soil Res. 18, $447-59$.

Brennan, R. F., Gartrell, J. W., and Robson, A. D. (1983). Reactions of copper with soil affecting its availability to plants. II. Effect of soil pH, soil sterilization and organic matter on the availability of applied copper. Aust. J. Soil Res. 21, 155-63.

Brennan, R. F., Gartrell, J. W., and Robson, A. D. (1984). Reactions of copper with soil affecting its availability to plants. III. Effect of incubation temperature. Aust. J. Soil Res. 22, $165-72$.

Brennan, R. F. Gartrell, J. W., and Robson, A. D. (1986). The decline in the availability to plants of applied copper fertilizer. Aust. J. Agric. Res. 37, 107-13.

Gartrell, J. W. (1980). Residual effectiveness of copper fertilizer for wheat in Western Australia. Aust. J. Exp. Agric. Anim. Husb. 20, 370-6.

Manning, D. C. (1975). Aspirating small volume samples in flame atomic absorption spectroscopy. At. Absorp. Newsl. 14, 99-102.

McBride, M. B. (1991). Processes of heavy and transition metal sorption by soil minerals. In 'Interactions at the Soil Colloid-Soil Solution Interface'. (Eds G. H. Bolt, M. F. De Boodt, M. H. B. Hayes and M. B. McBride.) pp. 149-75. (Kluwer Academic Publishers: Dordrecht.)

McLaren, R. G., and Crawford, D. V. (1973a). Studies on soil copper. I. The fractionation of copper in soils. J. Soil Sci. 24, 172-81.

McLaren, R. G., and Crawford, D. V. (1973b). Studies on soil copper. II. The specific adsorption of copper by soils. $J$. Soil Sci 24, 443-52.

MeLaren, R. G., Williams, J. G., and Swift, R. S. (1983). Some observations on the desorption and distribution behaviour of copper with soil components. J. Soil Sci. 33, 325-31.

Northcote, K. H. (1971). 'A Factual Key for the Recognition of Australian Soils.' (Rellim: Glenside, S. A.)

Shuman, L. M. (1985). Fractionation method for soil microelements. Soil Sci. 140, 11-22.

Swift, R. S., and McLaren, R. G. (1991). Micronutrient adsorption by soils and soil colloids. In 'Interactions at the Soil Colloid-Soil Solution Interface'. (Eds G. H. Bolt, M. F. De Boodt, M. H. B. Hayes and M. B. McBride.) pp. 257-92. (Kluwer Academic Publishers: Dordrecht.) 